\title{
Role of the eaeA Gene in Experimental Enteropathogenic Escherichia coli Infection
}

\author{
Michael S. Donnenberg, Carol O. Tacket, Stephen P. James, Genevieve Losonsky, James P. Nataro, \\ Steven S. Wasserman, James B. Kaper, and Myron M. Levine \\ Center for Vaccine Development, Division of Infectious Diseases; Division of Gastroenterology, Department of Medicine; \\ and Department of Pediatrics, University of Maryland, Baltimore, Maryland 21201; and Medical Service, \\ Department of Veterans Affairs Medical Center, Baltimore, Maryland 21201
}

\begin{abstract}
Enteropathogenic Escherichia coli (EPEC) infections are a leading cause of infant diarrhea in developing countries. Recently eaeA, a gene necessary for the characteristic intimate attachment of EPEC to epithelial cells in tissue culture, was described. We conducted a randomized, double-blind study to determine the role of the eae $A$ gene in human EPEC infection. 11 adult volunteers ingested $2 \times 10^{10}$ colony-forming units of 0127:H6 EPEC strain E2348/69, and an equal number received the same dose of an isogenic eae $A$ deletion mutant constructed from E2348/69. Volunteers were monitored for the development of diarrhea, fever, and systemic and gastrointestinal complaints. Diarrhea developed in all 11 volunteers who received E2348/69 and in 4 of 11 who received the mutant ( $P$ $=0.002)$. Fever was more common in recipients of the wildtype strain $(P=0.024)$. Stool volumes were lower in recipients of the mutant. All volunteers seroconverted to E2348/69 LPS, but the geometric mean peak titers of serum IgG and IgA in recipients of the mutant were lower than those of recipients of the wild-type strain. IgA against LPS was detected in the jejunal fluid of six of six recipients of E2348/69 and 5/6 recipients of the mutant. This study unambiguously assigns a role for eae $A$ as an EPEC virulence gene, but the residual diarrhea seen in recipients of the mutant indicates that other factors are involved. (J. Clin. Invest. 1993. 92:1412-1417.) Key words: virulence genes - microbial pathogenesis - diarrhea $\bullet$ immune response $\bullet$ fever
\end{abstract}

\section{Introduction}

Enteropathogenic Escherichia coli (EPEC) ${ }^{1}$ are a leading cause of diarrhea among infants on five continents (1-5). With the

This work was presented in preliminary form at the Annual Meeting of the Association of American Physicians, American Society for Clinical Research, and American Federation for Clinical Research, Baltimore, Maryland, 2 May 1992, and has appeared in abstract form (1992. Clin. Res. 40:214A).

Address correspondence to Michael S. Donnenberg, M.D., Division of Infectious Diseases, University of Maryland School of Medicine, MSTF 900, 10 South Pine Street, Baltimore, MD 21201.

Received for publication 31 December 1992 and in revised form 5 April 1993

1. Abbreviations used in this paper: ANCOVA, analysis of covariance; EAF, EPEC adherence factor; EPEC, enteropathogenic Escherichia coli.

J. Clin. Invest.

(C) The American Society for Clinical Investigation, Inc.

0021-9738/93/09/1412/06 \$2.00

Volume 92, September 1993, 1412-1417 advent of recombinant DNA technology, a detailed analysis of the complex process of EPEC infection at the molecular level is now possible. Indeed, much progress has recently been made in unraveling the genetic basis of EPEC pathogenesis. A three stage model has emerged from these analyses (6).

The initial phase of EPEC infection involves the nonintimate attachment of bacteria to intestinal epithelial cells. This process is recognized in tissue culture as localized adherence and is dependent on the presence of a large plasmid common to EPEC isolates (7). A bundle-forming pilus associated with the plasmid has been purified and proposed to mediate this initial adherence (8). Recently $b f p A$, the gene encoding the major structural subunit of the pilus, has been cloned and sequenced (9). The gene is part of an operon necessary for localized adherence and is related to genes encoding type IV fimbriae of several other pathogenic organisms, including Vibrio cholerae, Pseudomonas aeruginosa, and Neisseria gonorrhoeae. Transposon mutants at the $b f p A$ locus are deficient in localized adherence (9).

Subsequent to initial adherence, the bacterium becomes intimately attached to the epithelial cells and triggers a profound rearrangement of the host cell cytoskeleton. Although these events are collectively known as the attaching and effacing effect (10), analyses of mutants have indicated that the processes of intimate adherence and cytoskeletal disruption are separable. The signal transduced to the epithelial cell involves activation of host cell tyrosine kinases (11) and the release of calcium from intracellular stores $(12,13)$. The epithelial cell responds with the loss of microvilli and deposition of cytoskeletal components including filamentous actin (14), myosin (15), $\alpha$-actinin, talin, and ezrin (16) directly beneath the adherent bacteria. Tyrosine phosphorylation appears to be a necessary part of the signal received by the epithelial cell because tyrosine kinase inhibitors block the cytoskeletal changes (11). EPEC mutants have been isolated that are capable of both initial (localized) and intimate adherence, but are unable to activate host cell tyrosine kinases and induce the cytoskeletal changes (11).

Coincident with the cytoskeletal changes evoked in the epithelial cell, the bacterium becomes intimately attached to the host cell membrane (10). This step requires the function of a gene cluster located on the EPEC chromosome. The eaeA locus, originally designated eae (17), encodes a $94-\mathrm{kD}$ outer membrane protein called intimin (18). The predicted amino acid sequence of intimin shares extensive sequence similarities with the invasin proteins of Yersinia pseudotuberculosis and $Y$. enterocolitica, which mediate binding to members of the $\beta_{1}$ family of integrin proteins and subsequent cellular invasion (19). The $e a e B$ gene, located downstream of $e a e A$, and at least one other locus in this gene cluster are also necessary for intimate attachment (20). Mutants in the eaeA gene are capable of 
normal initial adherence and can activate host cell tyrosine kinases (11). Similar to wild-type strains, these mutants stimulate accumulation of host cell cytoskeletal proteins including filamentous actin, although the proteins are less intensely focused beneath the attached bacteria.

The profound changes in epithelial cells induced by attaching and effacing bacteria could lead to diarrhea by at least two mechanisms. The loss of microvilli could lead to malabsorption and osmotic diarrhea. Additionally, the rises in intracellular calcium concentration could lead to chloride secretion and secretory diarrhea (21). Since eaeA mutants are deficient in intimate attachment and are able to stimulate less profound changes in the epithelial cell cytoskeleton, we wanted to test the role of the eaeA gene in EPEC pathogenesis. Unfortunately, there exist no reliable animal models of EPEC infection. Although a variety of species demonstrate attaching and effacing lesions when infected with human EPEC strains, diarrhea does not develop reproducibly. Therefore, to investigate the role of the eaeA gene in the pathogenesis of EPEC infection, we conducted a volunteer study using isogenic wild-type and eaeA deletion mutant strains.

\section{Methods}

Bacterial strains. E2348/69 is a prototypic O127:H6 strain originally isolated from an outbreak of infant diarrhea in Taunton, England. A spontaneous nalidixic acid resistant clone, referred to herein as the wild-type strain, has been stored at $-70^{\circ} \mathrm{C}$ in $50 \%$ glycerol $/ 50 \%$ LuriaBurtani broth since it was last used in a volunteer trial in 1984 (22). CVD206 was derived from this clone by suicide vector-driven allelic exchange mutagenesis (23). It is isogenic to the wild-type strain except for an internal deletion of $1847 \mathrm{bp}$ from the eaeA gene ( 66\%). Only eight passages were required from recovery of wild-type from frozen storage to storage of the mutant strain. The phenotype of the mutant is identical to wild-type except for the inability to produce immunoreactive intimin, the product of the eaeA locus, and the inability to attach intimately to epithelial cells in tissue culture. The integrity of the construction of CVD206 was verified by restoration of the wild-type phenotype after introduction of the cloned wild-type eaeA allele on a plasmid (23).

Volunteers. Volunteers were healthy adults aged $18-40 \mathrm{yr}$ recruited from the Baltimore community. All underwent extensive screening including a history, physical examination, psychological examination, and laboratory testing. Serologic studies included tests for syphilis, hepatitis B surface antigen, and antibodies to human immunodeficiency virus. Prechallenge stools were examined for pathogenic bacteria, ova, and parasites. Written informed consent for participation in this study was obtained from each volunteer in accordance with the policies of the Institutional Review Board of the University of Maryland. In addition, each participant had to pass a written examination to insure a full understanding of the design and risks of the study.

Study design. This study was performed on the Research Isolation Ward of the Center for Vaccine Development (University of Maryland). The primary endpoint was the development of diarrhea, defined as the passage of at least one liquid stool weighing $300 \mathrm{~g}$ or more, or two or more liquid stools totaling at least $200 \mathrm{~g}$ during a 48 -h period. Secondary endpoints were the severity of diarrhea, defined as the total weight of diarrhea in those volunteers who had at least one liquid stool, and the occurrence of predefined symptoms. Volunteers were interviewed each day and questioned for the presence and severity of the following symptoms: anorexia, malaise, abdominal gurgling, abdominal cramps, vomiting, and headache. A symptom scale was used which assigned the severity of each symptom as 0 (not present), 1 (barely noticeable), 2 (clearly present, but able to continue activity), 3 (requiring bed rest), or 4 (worst experience of that symptom ever). In addition, oral temperature was recorded every $8 \mathrm{~h}$. Fever was defined as an oral temperature $\geq 37.8^{\circ} \mathrm{C}$. All stools were collected, examined, weighed, and cultured.

Intravenous fluid was administered to volunteers unable to take oral rehydration solution in quantities necessary to replace volume lost by diarrhea or emesis. After $96 \mathrm{~h}$ of observation all volunteers were treated with ciprofloxacin $500 \mathrm{mg}$ by mouth twice daily for $5 \mathrm{~d}$.

The study was designed as a randomized double-blind evaluation of the pathogenic potential of eaeA mutant strain CVD206 in comparison to E2348/69, the virulent wild-type strain from which it was derived. Blinding was maintained by the clinical coordinator, who was not involved in clinical evaluation of the volunteers. The challenge organism was plated from frozen storage onto trypticase soy agar. After $24 \mathrm{~h}$ at $37^{\circ} \mathrm{C}, 10$ colonies were picked, tested to confirm agglutination with 0127 antiserum, and spread on trypticase soy agar plates. A suspension of cells in $0.85 \%$ saline was made after growth for $20 \mathrm{~h}$ at $37^{\circ} \mathrm{C}$ and diluted to conform to the desired inoculum based on optical density. The actual inoculum given was confirmed by plate dilution. After an acclimatization period of $48 \mathrm{~h}$ in the inpatient unit, volunteers ingested the freshly prepared challenge inoculum. $2 \mathrm{~g}$ of sodium bicarbonate were dissolved in $150 \mathrm{ml}$ of distilled water. Volunteers ingested $120 \mathrm{ml}$ of sodium bicarbonate solution followed $1 \mathrm{~min}$ later by $2 \times 10^{10} \mathrm{CFU}$ of the challenge organism dissolved in $30 \mathrm{ml}$ sodium bicarbonate solution. Food and drink were proscribed for $90 \mathrm{~min}$ before and after challenge.

Microbiology. All stools were collected, weighed, and inoculated onto eosin-methylene blue agar plates containing $100 \mu \mathrm{g} / \mathrm{ml}$ nalidixic acid (to which the challenge organisms were resistant) for quantitative culture. 10 colonies typical of $E$. coli were picked and tested for agglutination with $\mathrm{O} 127$ antiserum. Hybridization with DNA probes derived from the EPEC adherence plasmid (24) and the eaeA gene (17) was performed on five colonies per stool as previously described. Rectal swabs were substituted for stool cultures in volunteers unable to produce a specimen during a $24-\mathrm{h}$ period. In addition, a duodenal specimen was obtained from each volunteer for culture using a gelatin string capsule 24 and $48 \mathrm{~h}$ after challenge. Only strings stained with bile and having a $\mathrm{pH} \geq 6$ were cultured. Fecal leukocytes were sought by Giemsa staining of the first liquid stool from each volunteer with diarrhea.

Endoscopy. As a second nested study, volunteers were asked to undergo esophagogastroduodenoscopy. Separate informed consent was secured. The clinical coordinator, who was not blinded to the identity of the group to which the volunteers belonged, selected three volunteers from each group who had agreed to endoscopy and who had the most diarrhea during the first $18 \mathrm{~h}$ of the study. These individuals underwent esophagogastroduodenoscopy under midazolam and meperidine anesthesia $\sim 24 \mathrm{~h}$ after challenge. A duodenal aspirate was obtained for culture and four duodenal biopsies were obtained for immunological studies (to be reported elsewhere) and histopathologic examination. Duodenal biopsies were fixed in $2 \%$ glutaraldehyde/ $1 \%$ formaldehyde and processed by routine methods for histopathology and scanning electron microscopy.

Serology. Serum was collected before challenge and 8,21 , and $28 \mathrm{~d}$ after challenge. Jejunal fluid was collected before and $8 \mathrm{~d}$ after challenge by aspiration through oral polyvinyl chloride intestinal tubes. Serum was tested for IgG and serum and duodenal fluid were tested for IgA antibodies against purified O127 LPS by ELISA as previously described $(22,25)$. Briefly, polystyrene Cooke plates were coated with the LPS preparation in carbonate coating buffer, $\mathrm{pH}$ 9.6. After an overnight incubation at $4^{\circ} \mathrm{C}$, plates were washed with $\mathrm{PBS}$, then blocked with PBS containing 5\% FBS for $1 \mathrm{~h}$ at $37^{\circ} \mathrm{C}$. Plates were again washed, and specimens added. Serum was initially diluted 1:50 followed by twofold dilutions; duodenal fluids were standardized to a total IgA content of $20 \mathrm{mg} \%$, then run at an initial dilution of $1: 4$. All specimens were diluted in PBS-Tween 20 with $1 \%$ FBS. Specimens were incubated overnight at $4^{\circ} \mathrm{C}$, plates washed, and the binding reaction measured using immunoglobulin specific alkaline phosphatase conjugates and substrate as previously described (25). Absorbances were read at $405 \mathrm{~nm}$ using an OD of 0.1 as a cut-off for a positive response. A 
fourfold rise in titer comparing prechallenge to postchallenge titers of antibody were considered to be indicative of a seroconversion.

Statistical analysis. For univariate analyses, categorical variables were compared using Fisher's exact test; continuous variables were compared using the Wilcoxon rank sum test or Spearman's rank correlation coefficient. Analysis of covariance (ANCOVA) was used to assess the relationship between challenge strain and peak immunoglobulin titer $($ covariate $=$ prechallenge titer $)$. For this analysis, immunoglobulin titers were logarithmically transformed to better approximate normality. Differences in the presence of symptoms caused by the challenge strains was assessed by discriminant analysis. For clinical outcomes, one-tailed $P$ values $\leq 0.05$ were considered significant. Twotailed tests were used to compare microbiological and immunological outcomes. Statistical tests were performed using SAS/PC (SAS Institute, Cary, NC).

\section{Results}

Clinical outcome. Clinical and serological data for each volunteer are given in Table I and summarized in Tables II and III. Diarrhea, as defined in Methods, developed in all 11 volunteers who received the wild-type strain, but in only 4 of 11 recipients of the eaeA deletion mutant $(P=0.002)$. When all volunteers who had liquid stools were compared regardless of whether they met the definition of diarrhea, illness was more severe in the group that received the wild-type strain $(P=0.004)$. However, when the analysis was restricted to volunteers who met the definition of diarrhea, the difference in stool weight be- tween groups was no longer significant. Fever was noted primarily in recipients of the wild-type strain (55 vs $9 \%, P$ $=0.024)$. Diarrhea developed after a mean incubation period of $7.4 \mathrm{~h}$ ( range $2.9-11.2 \mathrm{~h}$ ) in the group that received the wildtype strain, and $7.3 \mathrm{~h}$ (range 5.3-8.7 h) in the group that received the mutant strain. Independent comparisons of each symptom showed a higher frequency of anorexia, malaise, abdominal gurgling, and vomiting among recipients of the wildtype strain (Table I). However, these symptoms are not independent, but rather are manifestations of a common clinical syndrome. A discriminant analysis which simultaneously compared differences in frequency of all symptoms revealed significant differences between recipients of the wild-type and mutant strain $(P=0.005)$. In addition, a discriminant analysis comparing the peak score for each symptom also revealed differences in the severity of symptoms $(P=0.02)$.

Microbiology. The challenge organism was recovered from the stools of all volunteers. The peak excretion of the challenge strain was $1.1 \times 10^{8} \mathrm{CFU} / \mathrm{g}$ in recipients of the wild-type strain and $1.3 \times 10^{8} \mathrm{CFU} / \mathrm{g}$ in recipients of the mutant strain $(P$ $=0.68$ ). Duodenal strings were positive in only 3 of 16 volunteers who produced adequate specimens. One specimen was positive at $24 \mathrm{~h}$ from a recipient of the mutant strain, one at 24 $h$ from a recipient of the wild-type strain, and specimens obtained at both 24 and $48 \mathrm{~h}$ were positive from a recipient of the wild-type strain. Duodenal aspirates from individuals who underwent esophagogastroduodenoscopy did not yield $E$. coli. All

Table I. Number and Total Weight of Liquid Stools, Maximum Temperature, Peak Score of Symptoms, and ELISA Titers for Antilipopolysaccharide Antibodies in Recipients of the Wild-type and Mutant Strains

\begin{tabular}{|c|c|c|c|c|c|c|c|c|c|c|c|c|c|c|c|}
\hline \multirow[b]{2}{*}{ Volunteer no. } & \multirow{2}{*}{$\begin{array}{l}\text { No. of } \\
\text { liquid } \\
\text { stools }\end{array}$} & \multirow{2}{*}{$\begin{array}{l}\text { Weight of } \\
\text { liquid } \\
\text { stools }\end{array}$} & \multirow[b]{2}{*}{$\mathrm{T}_{\max }$} & \multicolumn{6}{|c|}{ Peak symptom score } & \multicolumn{2}{|c|}{ Serum IgG } & \multicolumn{2}{|c|}{ Serum IgA } & \multicolumn{2}{|c|}{ Secretory Ig } \\
\hline & & & & Anorexia & Malaise & Gurgling & Cramps & Headache & Vomiting & Pre & Peak & Pre & Peak & Pre & Post \\
\hline & & $g$ & $c$ & & & & & & & & & & & & \\
\hline \multicolumn{16}{|l|}{ Wild-type group } \\
\hline 1 & 2 & 458 & 37.3 & 0 & 0 & 1 & 0 & 0 & 0 & 25 & 12,800 & 25 & 400 & NA & NA \\
\hline 5 & 12 & 1,714 & 38.2 & 1 & 3 & 3 & 4 & 3 & 0 & 50 & 3,200 & 25 & 200 & 2 & 32 \\
\hline 6 & 8 & 3,403 & 37.2 & 1 & 1 & 1 & 3 & 1 & 4 & 100 & 1,600 & 25 & 1,600 & 4 & 128 \\
\hline 7 & 4 & 627 & 38.3 & 1 & 0 & 0 & 0 & 0 & 1 & 25 & 6,400 & 25 & 1,600 & NA & NA \\
\hline 9 & 9 & 967 & 37.9 & 1 & 1 & 1 & 3 & 2 & 1 & 50 & 12,800 & 50 & 12,800 & 4 & 256 \\
\hline 11 & 2 & 382 & 38.7 & 1 & 1 & 1 & 3 & 1 & 0 & 25 & 800 & 25 & 1,600 & 2 & 8 \\
\hline 12 & 2 & 515 & 37.7 & 1 & 1 & 4 & 0 & 0 & 0 & 25 & 400 & 25 & 1,600 & NA & NA \\
\hline 13 & 5 & 1,386 & 37.6 & 1 & 1 & 1 & 4 & 2 & 0 & 25 & 800 & 25 & 1,600 & 2 & 128 \\
\hline 15 & 15 & 1,730 & 37.6 & 0 & 1 & 1 & 2 & 0 & 0 & NA & NA & NA & NA & NA & NA \\
\hline 21 & 10 & 1,790 & 38.3 & 1 & 1 & 1 & 3 & 4 & 4 & 50 & 12,800 & 25 & 3,200 & 8 & 4,096 \\
\hline 25 & 13 & 3,528 & 38.4 & 1 & 1 & 0 & 4 & 0 & 3 & 25 & 3,200 & 25 & 800 & NA & NA \\
\hline \multicolumn{16}{|c|}{ eaeA Mutant group } \\
\hline 4 & 0 & 0 & 37.6 & 0 & 2 & 1 & 2 & 1 & 0 & 25 & 50 & 25 & 200 & 2 & 64 \\
\hline 8 & 2 & 234 & 36.8 & 1 & 3 & 0 & 3 & 1 & 0 & 50 & 800 & 50 & 1,600 & NA & NA \\
\hline 14 & 0 & 0 & 37.5 & 1 & 0 & 0 & 1 & 3 & 0 & 25 & 400 & 25 & 400 & 2 & 256 \\
\hline 16 & 9 & 1,104 & 37.6 & 1 & 1 & 0 & 3 & 3 & 2 & 25 & 100 & 25 & 100 & 2 & 32 \\
\hline 17 & 0 & 0 & 37.5 & 0 & 0 & 0 & 1 & 1 & 0 & 25 & 25 & 25 & 100 & 4 & 64 \\
\hline 18 & 2 & 196 & 38.1 & 0 & 1 & 0 & 0 & 0 & 0 & 25 & 50 & 25 & 200 & NA & NA \\
\hline 19 & 0 & 0 & 37.4 & 0 & 0 & 0 & 0 & 0 & 0 & 50 & 200 & 25 & 100 & 16 & 16 \\
\hline 20 & 1 & 254 & 37.1 & 0 & 0 & 0 & 0 & 0 & 0 & 25 & 50 & 25 & 1,600 & NA & NA \\
\hline 22 & 2 & 364 & 37.6 & 0 & 0 & 1 & 0 & 0 & 0 & 25 & 100 & 25 & 1,600 & 8 & 256 \\
\hline 23 & 3 & 827 & 37.2 & 0 & 0 & 1 & 0 & 0 & 0 & 50 & 200 & 25 & 800 & NA & NA \\
\hline 24 & 1 & 110 & 37.3 & 1 & 0 & 0 & 2 & 0 & 0 & 25 & 50 & 25 & 200 & NA & NA \\
\hline
\end{tabular}

NA, not available. 


\begin{tabular}{|c|c|c|c|}
\hline & \multicolumn{2}{|c|}{ Group } & \multirow{2}{*}{$\begin{array}{c}P \\
\text { (one-tailed) }\end{array}$} \\
\hline & Wild-type & eaeA Mutant & \\
\hline & $n=11$ & $n=11$ & \\
\hline Number with diarrhea* & $11(100 \%)$ & $4(36 \%)$ & 0.002 \\
\hline Median stool weight (in grams) in those with diarrhea (range) & $\begin{array}{l}1,386 \\
(382-3,403)\end{array}$ & $\begin{array}{l}596 \\
(234-1,104)\end{array}$ & 0.09 \\
\hline Number with at least one liquid stool & $11(100 \%)$ & $7(64 \%)$ & 0.045 \\
\hline Median stool weight (in grams) in those with at least one liquid stool (range) & $\begin{array}{l}1,386 \\
(382-3,403)\end{array}$ & $\begin{array}{l}254 \\
(110-1,104)\end{array}$ & 0.004 \\
\hline Number with fever $\left(\mathrm{T}_{\max } \geqslant 37.8^{\circ} \mathrm{C}\right)$ & $6(55 \%)$ & $1(9 \%)$ & 0.024 \\
\hline
\end{tabular}

${ }^{*}$ Defined as the passage of at least one liquid stool weighing $300 \mathrm{~g}$ or more, or two or more liquid stools totaling at least $200 \mathrm{~g}$ during a 48 -h period.

E. coli colonies that were agglutinated with 0127 antiserum from the group given the wild-type strain were positive with the eae gene probe. As expected, none of the $E$. coli colonies that were agglutinated with $\mathrm{O} 127$ antiserum from the group that received the mutant strain were eae probe positive, indicating lack of cross-contamination between groups. Of 130 samples from the group that received the wild-type strain, $108(83 \%)$ had at least one positive colony when tested with the EPEC adherence factor (EAF) probe. Only $45(48 \%)$ of 93 such samples from the group that received the mutant strain were EAF positive $(P<0.001)$. There was no correlation between the proportion of samples from an individual that were EAF positive and peak excretion. There was a significant association between proportion of samples from an individual that were EAF positive and severity of diarrhea as measured by total stool weight (Spearman's correlation coefficient $0.689, P$ $<0.001$ ). However, 76 of 80 samples recovered from both groups during the first $24 \mathrm{~h}$ after challenge, during the period of peak diarrhea, were EAF positive. Furthermore, there was no difference between groups in the proportion of volunteers that excreted at least one EAF negative sample during the study ( 8 of 11 recipients of the wild-type strain and 11 of 11 recipients of the mutant, $P=0.21$ ). Fecal leukocytes were detected in samples from only two volunteers. Both individuals were from the group that received the wild-type strain and both had fever.

Immunological response. All volunteers developed antibodies against O127 LPS (Tables I and III). A fourfold increase in serum IgG titer to LPS was detected in all recipients of the wild-type strain, but in only 5 of 11 recipients of the mutant strain $(P=0.001)$. The geometric mean of the peak serum IgG

Table III. Immunologic Response to O127 LPS by ELISA Titer in Recipients of Wild-type and eaeA Mutant EPEC

\begin{tabular}{lccc}
\hline & \multicolumn{2}{c}{ Geometric mean peak titer } & \\
\cline { 2 - 3 } & $\begin{array}{c}\text { Wild-type } \\
\text { group }\end{array}$ & $\begin{array}{c}\text { eaeA Mutant } \\
\text { group }\end{array}$ & \multirow{2}{*}{$P^{*}$} \\
\hline Serum IgG & 2,986 & 107 & $<0.001$ \\
Serum IgA & 1,300 & 353 & 0.005 \\
Secretory IgA (duodenal fluid) & 128 & 72 & 0.34 \\
\hline
\end{tabular}

* Analysis of covariance, two-tailed. titer was significantly higher in recipients of the wild-type strain (ANCOVA, $P<0.001$ ). All volunteers developed at least a fourfold rise in serum IgA antibodies against the LPS of the challenge organism. Again, the geometric mean peak titer was significantly higher in the recipients of the wild-type strain (ANCOVA, $P=0.005$ ). A fourfold rise in secretory IgA titer was detected in all of six recipients of the wild-type strain and five of six recipients of the mutant strain who were able to submit pre- and postchallenge duodenal aspirate specimens. There was no significant difference in the geometric mean titers of secretory $\operatorname{IgA}$ in the postchallenge duodenal specimen between the two groups (ANCOVA, $P=0.34$ ). A significant association existed between the proportion of samples recovered from an individual that were EAF probe positive and the peak serum IgG titer (Spearman's correlation coefficient $0.537, P=0.01$ ).

Histology. The duodenal biopsy samples obtained from all six samples appeared histologically normal by light microscopy. No bacteria were detected by light microscopy or by scanning electron microscopy.

\section{Discussion}

In this randomized, double-blind study we demonstrate that the eae $A$ locus is necessary for full pathogenicity in adult normal volunteers, thereby confirming the function of $e a e A$ as the first virulence gene to be identified in EPEC. Volunteers randomized to ingest an isogenic eaeA deletion mutant of prototypic EPEC strain E2348/69 were less likely to develop diarrhea than those who received the otherwise identical parent strain. Among volunteers with any loose stools, those from the cohort that received the mutant strain had less severe diarrhea than recipients of the wild-type strain. In addition, abdominal symptoms were milder in recipients of the eae $A$ mutant. These results demonstrate unambiguously that the eaeA gene is involved in EPEC virulence.

We found no difference in the peak excretion of the wildtype and mutant strains. This is not surprising considering that both strains are capable of producing the plasmid-encoded bundle forming pilus proposed to mediate the initial adherence of EPEC to epithelial cells in vitro $(8,9)$. The previously noted tendency of EPEC to lose the adherence plasmid during passage through adult volunteers was confirmed in this study (22). 
Surprisingly, a higher proportion of samples from volunteers who received the eaeA mutant were EAF probe negative. Thus the difference in incidence and severity of diarrhea between the groups that received the wild-type and mutant strains is confounded by the greater loss of the adherence plasmid (previously associated with virulence (22)) in the latter group. However, the fact that virtually all samples were EAF positive during the first $24 \mathrm{~h}$ of the study when diarrhea was at its maximum in both groups, suggests that loss of the EAF plasmid was not a cause of diminished virulence.

All volunteers had an antibody response against the LPS of the challenge organism. Serum IgA responses were noted in all and secretory $\operatorname{IgA}$ responses in all but one volunteer. However, volunteers from the cohort that received the wild-type strain were more likely to develop a fourfold rise in serum IgG against LPS. Furthermore the peak titers of both serum IgG and serum IgA against LPS were much higher in recipients of the wildtype strain. In contrast, no significant differences were apparent between the two groups in the titers of secretory IgA. Interestingly, eaeA mutants of EPEC are less invasive in vitro than wild-type organisms $(26,27)$. One possible explanation for the decreased immunogenicity of the eaeA mutant is that intimin is involved in presentation of EPEC LPS to the systemic immune system through limited invasion. The occurrence of fever almost exclusively in recipients of the wild-type strain may also reflect differences in invasion. In contrast, the failure to detect a difference between the groups in secretory IgA response to LPS indicates that local immunoglobulin responses may be generated efficiently in the absence of bacterial invasion, activation of the systemic immune system, or systemic symptoms.

The results of this study provide important information regarding the pathogenesis of EPEC diarrhea and allow us to speculate on the role of intimin in infection. The mechanisms by which EPEC causes diarrhea have not been identified. Unlike enterotoxigenic $E$. coli, EPEC do not induce increases in cellular cyclic nucleotides (28) and unlike enteroinvasive $E$. coli, EPEC do not cause dysentery. The hallmark of EPEC infection is the ability of the organism to attach intimately to the surface of epithelial cells and induce profound changes in cytoskeletal organization in a process known as attaching and effacing (10). Intimin, the $94-\mathrm{kD}$ outer membrane product of the eaeA locus, is necessary for the intimate attachment aspect of this effect in a tissue culture model $(17,23)$. In addition, enterohemorrhagic $E$. coli, which are also capable of the attaching and effacing effect, possess an eae $A$ gene homologue that is necessary for intimate attachment in a porcine model (29). We hypothesize that the EPEC eaeA mutant is unable to attach intimately to epithelial cells in humans and that this deficiency is reflected in the decreased virulence of the organism. Unfortunately, attempts to verify this hypothesis directly by endoscopic duodenal biopsy were unsuccessful. The duodenum was selected for the site of biopsy because previous studies in infants with persistent diarrhea due to EPEC have demonstrated organisms at this site $(30,31)$. However, cultures of duodenal aspirates obtained at the time of endoscopy did not yield $E$. coli in our adult volunteers. The failure to detect organisms or pathological changes in duodenal biopsies in this study suggests that the site of EPEC injury may differ between adults with acute, mild, experimental EPEC infection and infants with persistent, severe, natural EPEC infection.
The presumed failure of the eaeA mutant to attach intimately to intestinal epithelial cells is the most likely explanation for its decreased pathogenicity. Intimate attachment is necessary for full expression of the effects of EPEC on the host cell cytoskeleton $(17,23)$. Mutants at the eaeA locus remain capable, however, of more subtle cytoskeletal alterations and of inducing host-cell tyrosine kinase activity $(11,23,26)$. We speculate that this signal transduction event results in elevated intracellular calcium concentrations and fluid secretion (12). Loss of microvilli caused by EPEC attaching and effacing lesions is an alternative mechanism for EPEC diarrhea. While malabsorption may be a factor in protracted EPEC infection, the acute onset of diarrhea in volunteers (in as little as $2.9 \mathrm{~h}$ ) indicates that secretory mechanisms are also operative.

Interestingly, the eaeA mutant was not completely avirulent; diarrhea developed in 4 of 11 volunteers. Since diarrhea does not develop in volunteers who ingest nonpathogenic $E$. coli (32), this suggests that intimate attachment is not essential for the development of diarrhea. Indeed, the eaeA mutant remains capable of disrupting host cell cytoskeletal proteins and inducing cellular tyrosine kinase activity (11). Thus eae $A$ appears to be required for intimate attachment and full expression of cellular effects caused by other EPEC loci. It will therefore be interesting to test EPEC mutants deficient in signal transduction in volunteers.

In summary, we have shown that the eaeA gene of enteropathogenic Escherichia coli is necessary for full EPEC virulence, but that an eaeA mutant retains the ability to induce mild diarrhea. These results add to our understanding of EPEC pathogenesis and provide valuable information for the design of strategies to prevent and ameliorate diarrhea due to this prevalent pediatric pathogen.

\section{Acknowledgments}

We gratefully acknowledge the assistance of Kathleen Palmer and Brenda Berger in volunteer recruitment, clinical coordinator Sylvia O'Donnell, the nursing staff of the Research Isolation Ward, and the volunteers themselves.

This study was supported by contract N01 AI15096 and Public Health Service awards AI32074 and AI21657 from the National Institutes of Health.

\section{References}

1. Gurwith, M., D. Hinde, R. Gross, and B. Rowe. 1978. A prospective study of enteropathogenic Escherichia coli in endemic diarrheal disease. J. Infect. Dis. 137:292-297.

2. Gomes, T. A. T., M. A. M. Vieira, I. K. Wachsmuth, P. A. Blake, and L. R. Trabulsi. 1989. Serotype-specific prevalence of Escherichia coli strains with EPEC adherence factor genes in infants with and without diarrhea in São Paulo, Brazil. J. Infect. Dis. 160:131-135.

3. Kain, K. C., R. L. Barteluk, M. T. Kelly, H. Xin, G. D. Hua, G. Yuan, E. M. Proctor, S. Byrne, and H. G. Stiver. 1991. Etiology of childhood diarrhea in Beijing, China. J. Clin. Microbiol. 29:90-95.

4. Cobeljić, M., D. Mel, B. Arsić, L. Krstić, B. Sokolovski, B. Nikolovski, E. Sopovski, M. Kulauzov, and S. Kalenić. 1989. The association of enterotoxigenic and enteropathogenic Escherichia coli and other enteric pathogens with childhood diarrhoea in Yugoslavia. Epidemiol. Infect. 103:53-62.

5. Robins-Browne, R., C. S. Still, M. D. Miliotis, N. J. Richardson, H. J. Koornhof, I. Frieman, B. D. Schoub, G. Lecatsas, and E. Hartman. 1980. Summer diarrhoea in African infants and children. Arch. Dis. Child. 55:923-928.

6. Donnenberg, M. S., and J. B. Kaper. 1992. Minireview: enteropathogenic Escherichia coli. Infect. Immun. 60:3953-3961.

7. Baldini, M. M., J. B. Kaper, M. M. Levine, D. C. Candy, and H. W. Moon. 1983. Plasmid-mediated adhesion in enteropathogenic Escherichia coli. J. Pediatr. Gastroenterol. Nutr. 2:534-538. 
8. Girón, J. A., A. S. Y. Ho, and G. K. Schoolnik. 1991. An inducible bundleforming pilus of enteropathogenic Escherichia coli. Science (Wash. DC). 254:710-713

9. Donnenberg, M. S., J. A. Girón, J. P. Nataro, and J. B. Kaper. 1992. A plasmid-encoded type IV fimbrial gene of enteropathogenic Escherichia coli associated with localized adherence. Mol. Microbiol. 6:3427-3437.

10. Moon, H. W., S. C. Whipp, R. A. Argenzio, M. M. Levine, and R. A Giannella. 1983. Attaching and effacing activities of rabbit and human enteropathogenic Escherichia coli in pig and rabbit intestines. Infect. Immun. 41:13401351.

11. Rosenshine, I., M. S. Donnenberg, J. B. Kaper, and B. B. Finlay. 1992. Signal exchange between enteropathogenic Escherichia coli (EPEC) and epithelial cells: EPEC induce tyrosine phosphorylation of host cell protein to initiate cytoskeletal rearrangement and bacterial uptake. EMBO (Eur. Mol. Biol. Organ.) J. 11:3551-3560.

12. Baldwin, T. J., W. Ward, A. Aitken, S. Knutton, and P. H. Williams. 1991. Elevation of intracellular free calcium levels in HEp-2 cells infected with enteropathogenic Escherichia coli. Infect. Immun. 59:1599-1604.

13. Dytoc, M., L. Fedorko, and P. Sherman. 1991. Changes in cytosolic free calcium in HEp-2 cells infected with attaching and effacing Escherichia coli. $91 \mathrm{st}$ General Meeting of the American Society for Microbiology, Dallas, TX, 5-9 May 1991. B-108:43. (Abstr.)

14. Knutton, S., T. Baldwin, P. H. Williams, and A. S. McNeish. 1989. Actin accumulation at sites of bacterial adhesion to tissue culture cells: basis of a new diagnostic test for enteropathogenic and enterohemorrhagic Escherichia coli. In fect. Immun. 57:1290-1298.

15. Manjarrez-Hernandez, H. A., B. Amess, L. Sellers, T. J. Baldwin, S. Knutton, P. H. Williams, and A. Aitken. 1991. Purification of a $20 \mathrm{kDa}$ phosphoprotein from epithelial cells and identification as a myosin light chain: phosphorylation induced by enteropathogenic Escherichia coli and phorbol ester. FEBS (Fed Eur. Biochem. Soc.) Lett. 292:121-127.

16. Finlay, B. B., I. Rosenshine, M. S. Donnenberg, and J. B. Kaper. 1992. Cytoskeletal composition of attaching and effacing lesions associated with enteropathogenic Escherichia coli adherence to HeLa cells. Infect. Immun. 60:25412543.

17. Jerse, A. E., J. Yu, B. D. Tall, and J. B. Kaper. 1990. A genetic locus of enteropathogenic Escherichia coli necessary for the production of attaching and effacing lesions on tissue culture cells. Proc. Natl. Acad. Sci. USA. 87:7839-7843.

18. Jerse, A. E., and J. B. Kaper. 1991. The eae gene of enteropathogenic Escherichia coli encodes a 94-Kilodalton membrane protein, the expression of which is influenced by the EAF plasmid. Infect. Immun. 59:4302-4309.

19. Isberg, R. R., and J. M. Leong. 1990. Multiple $\beta_{1}$ chain integrins are receptors for Invasin, a protein that promotes bacterial penetration into mammalian cells. Cell. 60:861-871.
20. Donnenberg, M. S., J. Yu, and J. B. Kaper. 1993. A second chromosomal gene necessary for intimate attachment of enteropathogenic Escherichia coli to eptithelial cells. J. Bacteriol. In press.

21. Bolton, J. E., and M. Field. 1977. Ca ionophore-stimulated ion secretion in rabbit ileal mucosa: relation to actions of cyclic 3',5'-AMP and carbamylcholine. J. Membr. Biol. 35:159-173.

22. Levine, M. M., J. P. Nataro, H. Karch, M. M. Baldini, J. B. Kaper, R. E. Black, M. L. Clements, and A. D. O'Brien. 1985. The diarrheal response of humans to some classic serotypes of enteropathogenic Escherichia coli is dependent on a plasmid encoding an enteroadhesiveness factor. J. Infect. Dis. 152:550559.

23. Donnenberg, M. S., and J. B. Kaper. 1991. Construction of an eae deletion mutant of enteropathogenic Escherichia coli by using a positive-selection suicide vector. Infect. Immun. 59:4310-4317.

24. Nataro, J. P., M. M. Baldini, J. B. Kaper, R. E. Black, N. Bravo, and M. M. Levine. 1985. Detection of an adherence factor of enteropathogenic Escherichia coli with a DNA probe. J. Infect. Dis. 152:560-565.

25. Tacket, C. O., S. L. Moseley, B. Kay, G. Losonsky, and M. M. Levine. 1990. Challenge studies in volunteers using Escherichia coli strains with diffuse adherence to HEp-2 cells. J. Infect. Dis. 162:550-552.

26. Donnenberg M. S. S. B. Calderwood, A. Donohue-Rolfe, G. T. Keusch, and J. B. Kaper. 1990. Construction and analysis of Tn phoA mutants of enteropathogenic Escherichia coli unable to invade HEp-2 cells. Infect. Immun. 58:1565-1571.

27. Francis, C. L., A. E. Jerse, J. B. Kaper, and S. Falkow. 1991. Characterization of interactions of enteropathogenic Escherichia coli O127:H6 with mammalian cells in vitro. J. Infect. Dis. 164:693-703.

28. Long-Krug, S. A., C. S. Weikel, K. T. Tiemens, E. L. Hewlett, M. M. Levine, and R. L. Guerrant. 1984. Does enteropathogenic Escherichia coli produce heat-labile enterotoxin, heat-stable enterotoxins $a$ or $b$, or cholera toxin A subunits? Infect. Immun. 46:612-614.

29. Donnenberg, M. S., S. Tzipori, M. McKee, A. D. O'Brien, J. Alroy, and J. B. Kaper. 1993. The role of the eae locus of enterohemorrhagic Escherichia coli in intimate attachment in vitro and in a porcine model. J. Clin. Invest. 92:000000

30. Rothbaum, R., A. J. McAdams, R. Giannella, and J. C. Partin. 1982. A clinicopathological study of enterocyte-adherent Escherichia coli: a cause of protracted diarrhea in infants. Gastroenterology. 83:441-454.

31. Ulshen, M. H., and J. L. Rollo. 1980. Pathogenesis of Escherichia coli gastroenteritis in man-another mechanism. N. Engl. J. Med. 302:99-101.

32. Levine, M. M., E. J. Bergquist, D. R. Nalin, D. H. Waterman, R. B. Hornick, C. R. Young, S. Sotman, and B. Rowe. 1978. Escherichia coli strains that cause diarrhoea but do not produce heat-labile or heat-stable enterotoxins and are non-invasive. Lancet. i:1119-1122. 